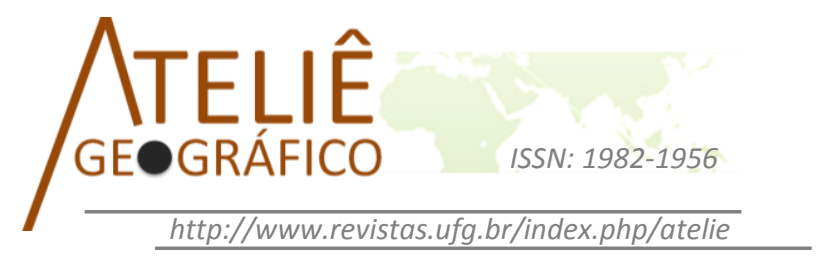

\title{
Globalização e tecnologia: olhares do Pantanal para o mundo
}

\author{
Globalization and Technology: \\ visions of the Pantanal for the world \\ La globalización y la tecnología: \\ visiones del Pantanal para el mundo
}

\author{
Mara Aline Ribeiro \\ Universidade Federal de Mato Grosso do Sul \\ mara_aline@yahoo.com.br \\ Edvaldo César Moretti \\ Universidade Federal da Grande Dourados \\ ecmoretti@hotmail.com
}

\begin{abstract}
Resumo
O Pantanal começou a ser ocupado e produzido pelo mundo moderno ocidental há aproximadamente duzentos anos, período em que assume as características sociais, culturais e econômicas valorizadas na atualidade como atrativo turístico. A partir da década de 1970 o processo conhecido como globalização, começa a ser gestado no Pantanal, com a inserção de tecnologias e práticas sociais promotoras de transformações em terras pantaneiras. Esse artigo tem por objetivo discutir, à luz da Geografia os efeitos da globalização, da ciência e da tecnologia na porção sul do Pantanal e os reflexos na comunidade pantaneira. O referencial teórico da Geografia revela as transformações econômicas e sociais no Pantanal ao ser inserido na totalidade mundo. Dentre as mudanças, pode-se destacar a introdução da tecnologia na vida profissional, como veículo ambíguo, onde a informação e a alienação, a serviço do capital, permeiam o universo das gentes pantaneiras.
\end{abstract}

Palavras-chave: Pantanal, globalização, tecnologia, gente pantaneira.

\begin{abstract}
The Pantanal began to be occupied and produced by the modern western world approximately two hundred years ago, the period during which it began to assume social, cultural and economic characteristics currently valorized as tourist attractions. From the 1970s, the process known as globalization began to be implanted in the Pantanal region with the insertion of technologies and social practices that promoted
\end{abstract}


transformations in these lands. This article purports to discuss - from the standpoint of Geography - the effects of globalization and the meanderings of modernity, of development, of science and technology in the southern portion of the Pantanal. The theoretical reference in Geography reveals the economic and social transformations in the Pantanl with its insertion in the world totality. Among these changes, we may stress the insertion of technology in professional life, as an ambiguous vehicle, where information and alienation, at the service of capital permeate the universe of the Pantanal people.

Key words: Pantanal, globalization, technology, the Pantanal people.

\begin{abstract}
Resúmen
El Pantanal comenzó a ser ocupado y producido por el mundo occidental moderno acerca de 200 años, período el cual asume las características sociales, culturales y económicas valorado hoy en dia como una atracción turística. Desde la década de 1970 el proceso conocido como globalización, comienza a ser concebido en el Pantanal, con la introducción de las tecnologías y prácticas sociales. Este artículo tiene por objeto analizar, a la luz de la geografía, los efectos de la globalización y las intrincaciones de la modernidad, el desarrollo, la ciencia y la tecnología en el Pantanal del sur. El referencial teórico de la Geografía revelan las transformaciones económicas y sociales en el Pantanal al se insertar en la totalidad mundo. Entre los cambios, se puede resaltar la inserción de la tecnología en la vida profesional, como un medio ambiguo, donde la información y el alienación, al servicio del capital, impregnan el universo de las personas de Pantanal.
\end{abstract}

Palabras clave: Pantanal, globalización, tecnología, personas del Pantanal.

\title{
Introdução
}

A globalização se apresenta como um processo dinâmico e ininterrupto, e, independente das diversas concepções sobre globalização, a forma como está posta na atualidade está relacionada com o avanço do capitalismo no Mundo Moderno, no qual o mercado dita as regras da economia mundial e da produção. Para Santos (2008): Trata-se de nova fase da história humana, [...] podemos, pois, admitir que a globalização constitui um paradigma para a compreensão dos diferentes aspectos da realidade contemporânea (SANTOS, 2008, p. 45).

Esse artigo tem por objetivo discutir, à luz da Geografia os efeitos da globalização, da ciência e da tecnologia na porção sul do Pantanal e os reflexos na comunidade pantaneira.

O método de aplicação da pesquisa em Geografia para compreender os olhares do Pantanal para o mundo, a partir da globalização e da tecnologia iniciou com minuciosa revisão bibliográfica, partiu do princípio da observação e do levantamento de dados por meio de registros fotográficos e de entrevistas estruturadas, coletados diretamente em campo, interpretados e analisados qualitativamente à luz da Geografia 
As ideias de Giddens (1999) e de Santos (2008) serviram de pressupostos teóricos para as análises sobre o processo de globalização, porque os referenciais desses autores envolvem, conjuntamente, as relações sociais. Segundo A. Giddens (1999), no livro As Consequências da Modernidade, a globalização abrange as relações sociais:

A globalização pode assim ser definida como a intensificação de relações sociais de escala mundial, relações que ligam localidades distantes de tal maneira que as ocorrências locais são moldadas por acontecimento que se dão a muitos quilômetros de distância, e vice-versa (GIDDENS, 1999, p. 64).

O pesquisador atribui as transformações sociais ocorridas no Mundo Moderno à globalização, independente das condições espaciais "A transformação local faz parte da globalização tanto como a extensão lateral das ligações sociais através do espaço e do tempo" (GIDDENS, 1999, p. 64).

Pode-se atribuir, também, à globalização as transformações sociais e econômicas pelas quais o Pantanal passa desde a década de 1970 para se inserir na "realidade contemporânea", porque, nas palavras de Santos (2010): "No mundo globalizado, o espaço geográfico ganha novos contornos, novas característica, novas definições" (SANTOS, 2010, p. 79).

Os redirecionamentos no espaço pantaneiro foram impostos pela totalidade mundo, sem a participação dos trabalhadores nas discussões que transformaram o cotidiano local. Para Bauman (1999) os investidores desconsideram e excluem a voz dos autóctones:

[...] os empregados, os fornecedores e os porta-vozes da comunidade não têm voz nas decisões que os investidores podem tomar; e que os verdadeiros tomadores de decisão, as 'pessoas que investem', têm o direito de descartar, de declarar irrelevante e inválido qualquer postulado que os demais possam fazer sobre a maneira como elas dirigem a companhia (BAUMAN, 1999, p. 13).

Para se manter competitivo no mercado mundial, os empresários do Pantanal precisaram da mediação do Estado, como facilitador da inserção dos produtos e serviços para comercialização. Giddens (1999) destaca: "A globalização é, em suma, um conjunto variado de processos que avançam graças a uma mistura de apoios políticos e económicos" (GIDDENS, 1999, p. 38). Os trabalhadores pantaneiros da mesma forma necessitaram se ajustar aos novos modelos da economia mundo, transformando as relações sociais, culturais e adaptando-se às inovações tecnológicas impostas. 
O processo de globalização adentrou terras pantaneiras com uma avalanche de transformações. Os arranjos da intervenção atingiram as gentes pantaneiras (proprietários de terras, trabalhadores das fazendas, proprietários dos empreendimentos turísticos e trabalhadores do turismo, que, independentes da origem, vivem e produzem no Pantanal), o meio ambiente e a produção, com todas suas facetas, gerando riquezas e misérias.

A discussão proposta no artigo se baliza na problemática da condução do mundo globalizado calcado na técnica e na tecnologia, responsáveis por imprimir aos produtos pantaneiros qualidades competitivas para rápida comercialização e retorno financeiro.

\section{A ciência, a tecnologia e o Pantanal a serviço do mercado}

A segunda metade do século XX caracterizou-se por importantes acontecimentos no Pantanal, dentre eles a divisão do Estado de Mato Grosso e a criação de uma nova Unidade da Federação, o Estado de Mato Grosso do Sul - na década de 1970 e a crise na pecuária, entre os anos de 1980 e 1990.

A separação do estado oficializou em 1977, e desde então o "novo" estado se mantém em quarto lugar no ranking dos maiores produtores de bovinos do país - dados do Censo Agropecuário de 2006 do Instituto Brasileiro de Geografia e Estatística - IBGE.

A criação do rebanho, exclusivamente extensiva, demandava técnica simples de manejo, o pasto nativo, com pouca suplementação nutricional, servia de alimentação para o gado, eventualmente havia controle das doenças por intermédio de vacinação e o uso de medicamentos se aplicava apenas em casos extremos.

Nesse período, a globalização emergia no mundo e para participar do competitivo mercado internacional, a opção para os produtores pantaneiros era aderir às novas técnicas e tecnologias de manejo do rebanho. A adesão demandava investimentos e, em meio a crise da pecuária, os fazendeiros, sem recursos suficientes para modernizar as fazendas, as vendeu para empresários de outros estados ou países.

A aplicação de novas e diferentes técnicas na criação do gado segue os ditames do mercado mundial, conforme Santos (2010) esclarece:

A globalização é, de certa forma, o ápice do processo de internacionalização do mundo capitalista. Para entendê-la, como, de resto, a qualquer fase da história, há dois elementos fundamentais a levar em conta: o estado das técnicas e o estado da política (SANTOS, 2010, p. 23). 
Um dos exemplos de inovação técnica no Pantanal é a utilização de pastagem cultivada para alimentação do rebanho bovino, iniciada na década de 1970, conforme relado do fazendeiro E29-11/11(Código de identificação pessoal dos entrevistados): "Eu tirei dinheiro para formar 500 hectares de pastagem no Pantanal. [...] Foi a primeira vez que se plantou pasto artificial no Pantanal. Isso foi em 1970, 1972. Eu consegui um gado com melhor qualidade e melhor rentabilidade" (E29-11/11).

A atenção com a saúde do rebanho também passou por reformulações asseguradas pelo Ministério da Agricultura, Pecuária e Abastecimento ao publicar o Manual de Legislação dos Programas Nacionais de Saúde Animal no Brasil, o qual estabelece normas de sanidade animal, exigidas pelo mercado mundial, quanto ao período de desmame, níveis nutricionais, controle por vacinação, dentre outras.

O reordenamento na forma de produção no Pantanal requisitou novos atores e novas tecnologias. Das fazendas elencadas para pesquisa, $90 \%$ contam com um quadro de profissionais qualificados, tais como administradores rurais, veterinários, zootecnistas e técnicos rurais. Aos peões coube a aprendizagem das novas técnicas, as quais, aliadas a experiência de campo e aos novos profissionais, contribuem para a diminuição na perda do rebanho e aumento da rentabilidade.

Novos profissionais, novas técnicas e, sobretudo, maior circulação de capital, desperta interesse das empresas de medicamentos veterinários, de suplementos animais, das universidades e dos centros de pesquisa, levando-os a financiar pesquisas científicas, a fim de garantir ao cliente o diferencial necessário para introduzir ou manter sua produção no mercado. Milton Santos (2008) assevera:

\footnotetext{
A ciência, a tecnologia e a informação estão na base mesma de todas as formas de utilização e funcionamento do espaço, da mesma forma que participam da criação de novos processos vitais e da produção de novas espécies (animais e vegetais). É a cientificização e a tecnicização da paisagem. É também a informatização, ou antes, a informacionalização do espaço (SANTOS, 2008, p. 48).
}

Das fazendas pesquisadas, $40 \%$ contam com o auxilio da ciência e da tecnologia no manejo do gado, independente do poder aquisitivo do proprietário, a ausência de energia elétrica em toda extensão do Pantanal, a dificuldade de acesso, sobretudo no período de cheia, e os custos elevados para implantação e manutenção de equipamentos eletrônicos de última geração, como, por exemplo, acesso à rede mundial de computadores, limita a introdução das "novidades" tecnológicas. 
Mesmo nessas condições, os proprietários de terras se mantêm competitivos no mercado, porque o uso de tecnologia, não é um impeditivo para os produtores estarem inseridos no circuito global de comercialização de gado (o leilão rural é uma alternativa de comércio para esses produtores rurais). Segundo Santos (2008) "Os sistemas técnicos criados recentemente se tornaram mundiais, mesmo que sua distribuição geográfica seja, como antes, irregular e o seu uso social seja, como antes, hierárquico" (SANTOS, 2008, p. 39). Dessa forma, a homogeneização mundial, disseminada nos discursos sobre a globalização, não retrata a realidade de locais sem elementos básicos, como por exemplo, energia elétrica e estradas.

A promoção de infraestrutura pública (estrada, energia, transporte) para viabilizar a produção e comercialização do produto pantaneiro é responsabilidade do Estado, enquanto regulador das finanças. Para Santos (2010),

[...] a vida de uma empresa vai além do mero processo técnico, de produção e alcança todo o entorno, a começar pelo próprio mercado e incluindo também as infraestruturas geográficas de apoio, sem o qual ela não pode ter êxito. É o Estado nacional que, afinal, regula o mundo financeiro e constrói infraestruturas, atribuindo, assim, a grandes empresas escolhidas a condição de sua viabilidade (SANTOS, 2010, p. 77).

Porém, os empresários pantaneiros entrevistados lamentam, com unanimidade, a negligência do Estado com relação a participação na expansão e manutenção da infraestrutura para melhoria nas condições de produtividade no Pantanal. Nas palavras do empresário da pecuária (E05-02/11):

\footnotetext{
As entidades brasileiras e o governo não estão virados para isso (infraestrutura). A estrada-parque é uma vergonha. Para qualquer negócio ir pra frente tem que ter comunicação e acesso. Aqui não tinha nada, não tinha energia. Essa rede de energia é privada. [...] Os celulares funcionam muito mal aqui. (E05-02/11).
}

Para acompanhar a dinâmica do capital e disponibilizar os produtos no mercado com rapidez, é imprescindível boas condições de transporte e comunicação. Segundo Marx (1996) "A revolução nos meios de produção da indústria e da agricultura tornaram necessária a revolução [...] nos meios de comunicação e transporte" (MARX, 19967, p. 384).

O período reconhecido como o da crise da atividade pecuária, aliado ao avanço do capitalismo no Mundo Moderno deu inicio ao reordenamento territorial, econômico e social no Pantanal. Harvey (2005) denomina esse tipo de crise de periódica e atribui a elas "o efeito de expandir a capacidade 
produtiva e de renovar as condições de acumulação adicional. Podemos conceber cada crise como uma mudança do processo de acumulação para um nível novo e superior" (Harvey, 2005, p. 47). No bojo da crise e das transformações, os empresários da pecuária vislumbraram formas alternativas de complementação dos lucros, como, por exemplo, o turismo.

Imbuídos no processo de desenvolvimento do turismo no Pantanal, empresários e representes dos governos estadual e federal iniciaram a reestruturação do território, com a implantação da Estrada-parque Pantanal, a pavimentação asfáltica da BR 262, a sensibilização ambiental, a adesão aos programas do governo federal de incentivo ao turismo, a criação de órgãos estaduais de regulamentação do turismo, como, por exemplo, a Fundação de Turismo de Mato Grosso do Sul. Além disso, o Pantanal foi projetado na mídia nacional e internacional e recebeu o título de Patrimônio Natural da Humanidade concedido pela UNESCO.

Os eventos elencados, coligados ao reencantamento da natureza no mundo moderno - a partir da Segunda Guerra Mundial, ao interesse pela conservação mundial, aos investimentos público e privado, e, principalmente a busca mundial pelo reencontro com a natureza, deu suporte à inserção do turismo como uma modalidade econômica na região, transformando o Pantanal em destino turístico.

Para manter o Pantanal em sintonia com o mundo global, com a ciência e a tecnologia foi necessária a implantação de novas formas estruturais, tais como: a construção da ponte sobre o rio Paraguai, a construção de pousadas com acesso à internet, a instalação da Base de Estudos do Pantanal da Universidade Federal de Mato Grosso do Sul, a expansão da rede de energia elétrica às margens da Estrada-parque, a instalação de torres para telefonia celular rural e antenas parabólicas, a adaptação dos veículos para o turismo, a modernização dos caminhões boiadeiros, a alteração na estrutura fundiária, entre outros. O estabelecimento dessas formas tem com consequência mudanças técnicas e sociais, porque produzem transformações estruturais de funcionamento das mesmas e alteram as relações socioeconômicas e com a natureza. Segundo Milton Santos (2009):

\footnotetext{
Quando a sociedade muda, o conjunto de suas funções muda em quantidade e em qualidade. Tais funções se realizam onde as condições de instalação se apresentam como melhores. Mas essas áreas geográficas de realização concreta da totalidade social têm papel exclusivamente funcional, enquanto as mudanças são globais e estruturais e abrangem a sociedade total, isto é, o Mundo, ou a Formação socioeconômica (SANTOS, 2009, p. 116).
} 
Em outra obra, o mesmo autor analisa os efeitos das transformações no território, responsáveis pela construção de outra geografia:

Os espaços rural e urbano são marcados, na sua transformação,
pelo uso sistemático das contribuições da ciência e da técnica e
por decisões de mudança que, no campo e na cidade levam em
conta os usos a que cada fração do território vai ser destinada,
trata-se de uma geografia completamente nova (SANTOS, 2008,
p. 118).

A introdução dos setores econômicos do Pantanal no mercado globalizado atende a demanda mundial, a totalidade mundo imprime novos caminhos para a produção espacial do Pantanal e, consequentemente para as gentes pantaneiras. A chegada de novos atores (turistas, trabalhadores do turismo e da pecuária) juntamente com a introdução de novas técnicas e tecnologias alterou o modo de vida da comunidade local. Assim, no bojo das transformações econômicas e sociais surge outra Geografia no espaço pantaneiro.

\section{Os efeitos da globalização no modo de vida das "gentes pantaneiras"}

O uso de novas tecnologias, sobretudo, na comunicação e no transporte, contribuiu com a entrada do Pantanal no mundo globalizado e está interferirindo diretamente na vida social e cultural da comunidade pantaneira. As palavras de Paul Claval (2012) explicam os efeitos da globalização no cotidiano das pessoas:

A globalização não afeta apenas a distribuição das atividades econômicas, da renda gerada e as populações que compartilham delas. O aumento da mobilidade e a aceleração da mudança alteram o cenário cultural e comprometem as identidades até então aceitas. (CLAVAL, 2012, p. 357. Trad. da autora).

Tanto os proprietários de terras, quanto os trabalhadores, viram-se diante de redirecionamentos sociais e espaciais que alteraram o cotidiano pantaneiro, como, por exemplo, a chegada de outros atores ao Pantanal, em busca de oportunidades de emprego, de investimento e de lazer.

Familiarizados com as técnicas centenárias na lida com o gado, as primeiras investidas das novas formas de produção (modernização da pecuária e divisão do espaço com o turismo), a partir da década de 1970 teve resistência por parte das gentes pantaneiras, "Eu fui expulso de muitas fazendas na época, com os turistas e tudo. Eles falavam: 'Não pode entrar!' Me punham de porteira à fora" afirma (E11-02/11) em entrevista. O fazendeiro E29-11/11 tece 
comentário referindo-se à produção pecuária "Em 1970 eu comecei a plantar pasto. Falavam assim: 'Ele tá plantando pasto? Eu não vou plantar, vou esperar ele quebrar"' (29-11/11).

Segundo David Harvey (2005) "O surgimento de uma estrutura especial diferente com a ascensão do capitalismo não é um processo livre de contradições" (HARVEY, 2005, p. 53). Assim, as mudanças desencadearam conflitos e desafios, dentre eles, a aprendizagem de novas técnicas nas diferentes formas de produção impostas em terras pantaneiras, e, sobretudo, a construção de novas relações com a natureza e entre as pessoas.

Em entrevista E34-04/12, trabalhador da pecuária, expõe as dificuldades em entender o novo processo pelo qual o Pantanal está passando "O Pantanal tá muito mudado. É difícil isso, tem muito pasto feito, não é como antigamente tudo pasto nativo" (E34-04/12).

O trabalhador do turismo E09-02/11 também relata as dificuldades pessoais em compreender o processo de transformação no qual está inserido:

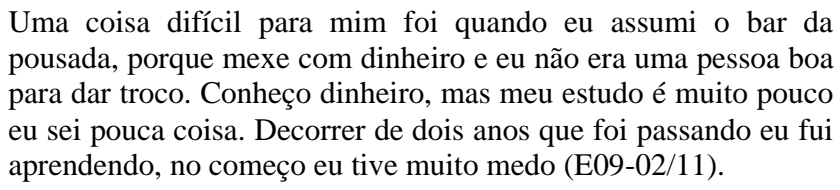

Os períodos de dificuldades, normalmente, vêm acompanhados de novas aprendizagens e experiências. Nesse sentido, as gentes pantaneiras, sobretudo trabalhadoras do turismo, aprenderam e começaram a utilizar avançados meios de comunicação, como, por exemplo, a internet no trabalho, no lazer ou como recurso para os estudos.

Dentre os trabalhadores do turismo entrevistados, $60 \%$ utilizam a internet diariamente, conforme exemplifica o monitor ambiental E02-02/11 "Eu uso muito internet, pego meu computador pra ver e-mail, ligo pra minha mãe no skype, falo com ela sempre que posso, com minha namorada em Londres". A gerente de pousada E16-05/11 garante a continuidade do estudo ao afirmar: "Eu estudo a distância, daqui da pousada mesmo" (E16-05/11).

A despeito da utilização da internet como veículo de integração entre a comunidade pantaneira e o mundo, a adesão ainda é insipiente, um dos motivos é o alto custo de instalação e manutenção dos equipamentos, as palavras de Bauman (1999) representam o momento atual no Pantanal:

Ao contrário do que costumam acreditar os acadêmicos, eles próprios integrantes da nova elite global, a Internet e a Web não 
são para qualquer um, e é improvável que jamais venham a se abrir para o uso universal (BAUMAN, 1999, p. 60/61).

Considerando o acesso à internet restrito entre as gentes pantaneiras, grande parte da comunidade pantaneira está à margem desse tipo de tecnologia, cabendo-lhes apenas as ondas do rádio e da televisão, como veículo de informação e de lazer com interatividade comprometida. Segundo Bauman (1999):

\begin{abstract}
A elogiadíssima 'interatividade' do novo veículo é um grande exagero; deveriam antes falar num 'meio interativo one-way'. [...] Quanto aos demais, abandonados à rede de TV por satélite ou a cabo, sem qualquer pretensão de simetria entre os dois lados da tela, o seu quinhão é a pura e simples observação. [...] Segregados e separados na terra, os habitantes locais encontram os globais através das transmissões regulares do céu pela TV (BAUMAN, 1999, p. 61/62).
\end{abstract}

A aquisição de um televisor é resultado da ascensão do capital entre a população mundial e do fortalecimento da indústria eletroeletrônica. Os pesquisadores Caparelli e Lima (2004) afirmam: “[...] a televisão no Brasil deu continuidade ao objetivo capitalista de produção, oferecendo novas possibilidades ao capital" (CAPARELLI e LIMA, 2004, p.62).

A imagem da televisão é composta por uma gama de produtos utilizados na e para a televisão, intermediado publicidade. Cancio (2005) assevera: "A publicidade está relacionada diretamente com o processo histórico da televisão brasileira: o fator econômico impulsionado pela publicidade, a principal fonte de receita das emissoras" (CANCIO, 2005, p. 91).

O trabalho de marketing das grandes lojas de eletrodomésticos é abrangente e facilita a aquisição dos equipamentos em ofertas promocionais. Variadas marcas, formas de pagamento e proposta de entrega em todos os lugares do país atraem consumidores ávidos pela mercadoria. Assim, independente das distâncias dos centros comerciais, modernos aparelhos de rádio e de televisão fazem parte do cotidiano das gentes pantaneiras.

Mesmo nas fazendas, com energia gerada por "Grupo Gerador de Energia Elétrica a óleo diesel", a televisão tem sua função garantida entre as gentes pantaneiras. O empresário pantaneiro E1-12/10 afirma em entrevista: “A televisão hoje tá um ponto assim: Se a sua funcionária não assistir a novela, você não consegue mantê-la lá" (E1-12/10). Logo, trata-se de uma condição para a permanência dos empregados no local de trabalho, não de uma conquista dos trabalhadores ou benfeitorias por parte dos patrões. 
Nos pantanais do Abobral e do Aquidauana a população tem acesso à programação da TV aberta por antena parabólica, a qual capta a sintonia via satélite, porém, restringe os sinais das TVs regionais. A indisponibilidade da programação local e regional à comunidade pantaneira os mantém alienados e com informações limitadas. Pesquisadores como Dabona e Fontenella (1996) asseguram a importância da TV regional ao afirmar: "A TV regional pode servir para desenvolver as características culturais de cada comunidade, combatendo uma homogeneização que poderia ser causada pelas grandes redes de comunicação" (DABONA E FONTENELLA, 1996, p. 96).

Cancio (2005) insiste na valorização da comunicação local e regional ao garantir:

\begin{abstract}
As noticias locais tornam-se importantes à medida que o telespectador se volta para os acontecimentos que estão mais próximos de usa área de interesse. Notícias que estão relacionadas com seu estado, sua cidade, seu bairro, sua cultura. As notícias nacionais têm importância por sua abrangência e repercussão, mas a regionais não podem ser desprezada (CANCIO, 2005, p. 101).
\end{abstract}

Os telespectadores, via antenas parabólicas, algumas vezes são informados dos acontecimentos regionais por intermédio dos telejornais de abrangência nacional, ou seja, pela TV global, a despeito de terem assegurado o acesso à programação regional, pela Constituição Federal de 1988, Capítulo V, Art. 221, item III - "regionalização da produção cultural, artística e jornalística, conforme percentuais estabelecidos em lei”.

A falta de conhecimento das noticias regionais e locais deixa a gente pantaneira vulnerável e à parte, por exemplo, das negociações salariais entre os órgãos de representação do trabalhador rural e do produtor rural, divulgadas pela imprensa regional, sujeitando-os aos "acordos" salarias, unilaterais, entre patrões e empregados. O entrevistado E28-07/11 fala sutilmente do "acordo", exalta a importância da carteira de trabalho assinada e o salário mensal "Minha carteira está assinada como capataz de fazenda. Eu fechei (acordo) nos 900 conto $(\mathrm{R} \$ 900,00)$. Eu vim como funcionário dele pra trabalhar e domá essa tropa por 900 conto (E28-07/11)".

No Mato Grosso do Sul o salário mínimo rural é de $\mathrm{R} \$ 665,00$ (http://www.srcg.com.br) e cada função exercida tem piso salarial correspondente. Ao comparar o salário do capataz da fazenda E28-07/11, com a planilha do Sindicato Rural de Campo Grande/MS, os R \$ 900,00 acordados não cumpre com o piso salarial de $\mathrm{R} \$ 1.218,91$, estabelecido para os capatazes de campo. Além disso, considerando a informação a respeito do trabalho na 
doma da tropa, deveria ser acrescentado $\mathrm{R} \$ 296,96$ como gratificação por cada animal domado.

Existe um conflito entre os valores estabelecidos pelos órgãos de representação dos trabalhadores rurais e a realidade salarial dos trabalhadores pantaneiros.

As gentes pantaneiras, sobretudo os trabalhadores das fazendas, garantem estima, consideração e agradecimento às qualidades do empregador. A entrevistada E35-05/12 garante: "O patrão é bom, só tem um problema, ele não assina a carteira. Ele é um ótimo patrão. Só que é difícil ele pagá o salário" (E35-05/12).

A fala da trabalhadora rural E35-05/12 ao tecer elogios ao patrão, mesmo em situação trabalhista irregular, pode ser entendida como uma forma de alienação por falta de informação, pois, independente das qualidades do patrão qualquer trabalhador tem o direito, resguardado por lei, ao recebimento de salário mensal e dos benefícios previdenciários.

Em contraposição a alienação provocada, em parte, pela televisão é importante a intervenção do Estado, por intermédio, principalmente, da educação. Para Giddens (1999), o governo no mundo contemporâneo existe para "promover o desenvolvimento activo do capital humano através do seu papel fundamental no sistema de ensino" (GIDDENS, 1999, p. 49). Nesse sentido, o Estado deve assegurar educação, a qual oportunizará a gente pantaneira, conhecimento para entender a dinâmica social e formatar ideias despojadas dos "favores" e dos "acordos" com os patrões.

O Código Nacional de Telecomunicações, instituído pela Lei Federal $\mathrm{N}^{\circ}$ 4.117, de 27 de agosto de 1962, no parágrafo único do Art. 67, assume um compromisso com a educação ao atribuir obrigações educacionais aos meios de comunicação e condicionar a renovação dos contratos, de concessão dos canais de televisão, à inserção de programas educativos:

Parágrafo único. O direito a renovação decorre do cumprimento pela empresa, de seu contrato de concessão ou permissão, das exigências legais e regulamentares, bem como das finalidades educacionais, culturais e morais a que se obrigou, e de persistirem a possibilidade técnica e o interesse público em sua existência (LEI FEDERAL N 4.117, DE 27 DE AGOSTO DE 1962).

O cumprimento, regulamentação e fiscalização dessas obrigações legais não são objetos de análise nesse artigo, o qual, apenas pontua a existência das leis e decretos no sistema de comunicação brasileiro, que asseguram programas educativos nas grades de programação das TVs. 
Sendo assim, melhores condições técnicas em consonância com a educação e, sobretudo, o cumprimento das leis, podem se tornar elementos importantes para a formação de indivíduos capazes de compreender o mundo e aptos a fazer escolhas.

\section{Considerações Finais}

A globalização é um processo abrangente independente da condição social, econômica ou das escolhas pessoais. Todas as instituições, empresas e pessoas vivem, na atualidade, sob os ditames da totalidade mundo promovidos pela globalização.

Os avanços tecnológicos, sobretudo dos meios de comunicação, aproximaram a comunidade pantaneira dos acontecimentos mundiais. As imagens da televisão, além de ser um veículo de informação, também, estão a serviço da publicidade com objetivo de vender produtos, obter lucro e como instrumento manipulador do capitalismo a serviço do mercado mundial.

O processo de globalização ao qual o Pantanal está inserido, principalmente, pelo uso das tecnologias de comunicação, é conflitante porque, concomitantemente, tem o poder de manipular e de se aliar às gentes pantaneiras. $\mathrm{O}$ acesso à informação, na atualidade é condição básica, dentro da dinâmica mundial, para a manutenção dos produtos pantaneiros no mercado, garantindo emprego e renda para a população local.

\section{Referências}

ARAÚJO, A. P. C. \& BICALHO, A. M. S. M. O rural em movimento: a pecuária nas transformações espaciais do Pantanal. Campo Grande, MS: Ed. UFMS, 2010.

BANDUCCI JR, Á. A natureza do pantaneiro. Relações sociais e representação de mundo no "Pantanal da Nhecolândia". Campo Grande: Editora UFMS, 2007.

BARROS, A. L. Gente pantaneira. Crônicas da sua História. Rio de Janeiro: Lacerda Editores, 1998.

BAUMAN, Z. Globalização: as consequências humanas. Trad., Marcus Penchel. Rio de Janeiro: Jorge Zahar Ed., 1999.

BRASIL. Constituição (1988). Constituição da República Federativa do Brasil: promulgada em 5 de outubro de 1988. Atualizada com as Emendas Constitucionais Promulgadas.Brasília, DF: Senado, 1988. 
BRASIL. Decreto-Lei No 236, de 28 de fevereiro de 1967. Disponível em: http://www.planalto.gov.br/

BRASIL, Lei Federal No 4.117, de 27 de agosto de 1962. Institui o Código Nacional de Telecomunicações. Disponível em: http://www.planalto.gov.br/

CALLAI, H. C. Estudar o lugar para compreender o mundo. In: CASTROGIOVANNI, A. C. (Org.) Ensino de Geografia: práticas e textualizações no cotidiano. Porto Alegre: Mediação, 2000.

CANCIO, M. Telejornalismo Descoberto - a origem da notícia no jornalismo televisivo regional. Campo Grande: Editora UFMS, 2005.

CANCIO, M. Televisão fronteiriça: TV e telejornalismo na fronteira do Brasil e Paraguai. Campo Grande: Ed. UFMS, 2011.

CAPPARELLI, S. \& LIMA, V. A. Comunicação e televisão: desafios da pósglobalização. São Paulo: Hacker, 2004.

CASTORIADIS, C. As encruzilhadas do labirinto II - domínios do homem. 2. Ed. Trad., José Oscar de Almeida Marques. Rio de Janeiro: Paz e Terra, 1987.

CLAVAL, P. De la terrre aux hommes: lá géographie comme vision du monde. Paris: Armand Colin, 2012.

CORRÊA, R. L. Territorialidade e corporação: um exemplo. In: SANTOS, M., SOUZA, M. A. \& SILVEIRA, M. L. (Org.) Território: globalização $e$ fragmentação. São Paulo: HUCITEC-AMPUR, 1996. 3. ed. (p. 251-256).

DEBONA, D. L.; FONTELLA, O. M. Telejornalismo global x regional. In:

VENEZA, Mayora Ronsini (org.), Sociedade, Mídia \& Cultura. Santa Maria:

Capes, 1996.

EMBRAPA PANTANAL. Disponível em: http://www.embrapa.gov.br/

GIDDENS, A. As Consequências da Modernidade. 2. ed., Oeiras/PT: Celta Editora, 1990.

GIDDENS, A. Para uma terceira via: a renovação da social-democracia. Trad. Saul Barata. Lisboa: Editorial Presença, 1999.

HAESBAERT, R. \& PORTO-GONÇALVES, C. W. A nova des-ordem mundial. São Paulo: Editora UNESP, 2006.

HALL, S. A identidade cultural na pós-modernidade. 11. ed. Rio de Janeiro: DP\&A, 2004.

HARVEY, D. A produção capitalista do espaço. Trad. Carlos Szlak. 2. ed. São Paulo: Annablume, 2005.

IANNI, O. A ocidentalização do mundo. In: A sociedade global. Rio de Janeiro: Civilização Brasileira, 1997. 
INSTITUTO BRASILEIRO DE MEIO AMBIENTE E RECURSOS RENOVÁVEIS. Disponível em: http://www.ibama.gov.br/

INSTITUTO BRASILEIRO DE GEOGRAFIA E ESTATÍSTICA. Disponível em: http://www.ibge.gov.br

JAMBEIRO, O. Regulando a TV: uma visão comparativa no Mercosul. Salvador: EDUFBA, 2000.

LEFEBVRE, H. A reprodução das relações de produção. Porto (Portugal): Pubicações Escorpião - Cadernos O Homeme e a Sociaedade, 1973. p. 115.

MARTINS, J. S. A sociabilidade do homem simples: cotidiano e história na modernidade anômala. 3. ed., $1^{a}$ reimpressão. São Paulo: Contexto, 2012.

MARX, K. O Capital: crítica da economia política. Vol I. Tomo I. São Paulo: Nova Cultural, 1996.

MARX, K. \& ENGELS, F. A ideologia alemã. 4. ed. Portugal: Editorial Presença, 1980 , v. I e II.

MINISTÉRIO DA AGRICULTURA, PECUÁRIA E ABASTECIMENTO. Disponível em: http://www.agricultura.gov.br/animal/sanidade-animal

MOREIRA, R. Pensar e ser em geografia: ensaios de história, epistemologia e ontologia do espaço geográfico. 1. ed., $1^{\mathrm{a}}$ reimpressão. São Paulo: Contexto, 2008.

MORETTI. E. C. Atividade turística no Pantanal e as transformações no trabalho. Revista de geografia, Campo Grande: UFMS, ano V, n. 9, janeiro-junho de 1999.

MORETTI. E. C. Paraíso visível e real oculto. Campo Grande, MS: Ed. UFMS, 2006.

NOGUEIRA. A. X. Pantanal, homem e cultura. Campo Grande: Editora UFMS, 2002.

PORTO-GONÇALVES, C. W. Os (des)caminhos do meio ambiente. 2. ed., São Paulo: Contexto, 1990.

PORTO-GONÇALVES, C. W. A globalização da natureza e a natureza da globalização. Rio de Janeiro: Civilização Brasileira, 2006.

RODRIGUES, A. M. Produção e consumo do e no espaço: problemática ambiental urbana. São Paulo: HUCITEC, 1998.

SANTOS, B. de S. Desigualdad, exclusión y globalización: hacia la construcción multicultural de la igualdad y la diferencia. Revista de Interculturalidad, n. 1, octubre 2004 - enero 2005. Universidad de Chile, Santiago, Chile.

SANTOS, B. de S. Globalizations. Theory, Culture \& Society. Disponível em: http://tcs.sagepub.com. 
SANTOS, B. de S. Um discurso sobre as ciências. 7. ed. São Paulo: Cortez, 2010.

SANTOS, M. Natureza do espaço. 4. ed. 5. reimpr. - São Paulo: EDUSP, 2009.

SANTOS, M. Técnica, espaço, tempo: globalização e meio técnico científicoinformacional. 5. ed. - São Paulo: Editora da Universidade de São Paulo, 2008.

SANTOS, M. Por uma outra globalização: do pensamento único à consciência universal. Rio de Janeiro: Record, 2010.

SINDICATO RURAL DE CAMPO GRANDE. Disponível em: http://www.srcg.com.br

SMITH, Neil. Desenvolvimento Desigual. Rio de Janeiro: Editora Bertrand Brasil S.A., 1988.

SOUZA, M. A. Governo Urbano. São Paulo, Nobel, 1988.

THOMAS, K. O homem e o mundo natural. São Paulo: Companhia das Letras, 2010.

WALTERS, M. Admiráveis mundos novos: teorias recentes. In: Globalização. Oeiras: Celta, 1999.

Mara Aline Ribeiro

Doutoranda do Instituto de Geografia da Universidade Estadual de Campinas-SP.

Docente na Universidade Federal de Mato Grosso do Sul.

Cidade Universitária - Caixa Postal 649, Prédio do CCHS - CEP: 79.070-900 - Campo

Grande (MS) - Brasil

E-mail: mara_aline@yahoo.com.br

Edvaldo César Moretti

Bolsista Produtividade CNPq. Doutor em Geografia pela Universidade Estadual Paulista

Júlio de Mesquita Filho.

Docente na Universidade Federal da Grande Dourados.

Rodovia Dourados-Itahum, km 12. Prédio da FCH, Cidade Universitária, CEP: 79.804-

970 - Dourados (MS) - Brasil

E-mail: ecmoretti@hotmail.com

Recebido para publicação em outubro de 2013

Aprovado para publicação em janeiro de 2014 